\title{
THE EFFECT OF FURFURAL UPON THE GERMINATION AND RESPIRATION OF ASCOSPORES OF NEUROSPORA TETRASPERMA ${ }^{1}$
}

\author{
Alfred S. Sussman
}

THE woRk of Emerson (1948) showed for the first time that chemical treatment, as well as the application of heat (Goddard 1935, 1939), could activate ascospores of Neurospora. She reported that furfural and furfuryl alcohol in very low concentrations effectively induced germination, but the mechanism of this activating effect was not investigated. Since that time, Sussman (1953) has reported that 11 other heterocyclics also serve as activators of ascospores. The purpose of the following experiments was to follow up these observations with an investigation of the metabolic effects of chemical activators.

Materials and METhods.-Ascospores were obtained by crossing strains 374 and 377 of Neurospora tetrasperma which were then grown as outlined by Goddard (1935). Since Emerson (personal communication, 1951) has shown that ascospores rapidly lose their sensitivity to chemical activators, these were used within a month after harvesting (fresh spores). In the experiments wherein the ageing effect or loss of sensitivity was studied, "old" spores were used: these had been harvested at least 6 mo. before use. Both "fresh" and "old" ascospores were stored at $4{ }^{\circ} \mathrm{C}$. at 65 per cent relative humidity.

Respiratory measurements were made in Warburg vessels of $7 \mathrm{ml}$. capacity with a fluid volume of $1.1 \mathrm{ml}$. Standard Warburg manometers were used at a shaking rate of 120 oscillations per minute, while the temperature of the bath was maintained at $26^{\circ} \mathrm{C}$. except when otherwise stated. Anaerobic conditions were obtained by flushing the vessels with nitrogen which had been passed through alkaline pyrogallol and then over a heated copper coil to remove contaminant $\mathrm{CO}_{2}$ and $\mathrm{O}_{2}$.

Spore suspensions for the respirometric determinations were made up by determining the volume of a weighed sample of spores after centrifuging in a hematocrit tube. The spores were then washed with a $1: 4$ dilution of sodium hypochlorite (Fishers reagent grade) to kill contaminant conidia, rinsed several times in distilled water, and finally resuspended in 30 parts of distilled water (by volume). Controls of dormant spores suspended in water were always run. The rate of oxygen uptake remained constant; therefore, it was assumed that contamination was controlled effectively.

Spores were heat activated by suspending them in distilled water at $60^{\circ} \mathrm{C}$. for $30 \mathrm{~min}$. in a constant temperature oil bath. Chemical activation was usu-

1 Received for publication November 25, 1952.

This work was made possible by generous grants from the Committee on Growth of the American Cancer Sóciety and the Rackham Fund of the University of Michigan. ally performed by tipping vacuum distilled furfural from the side arm of the Warburg vessel or by "preactivating" by shaking with furfural for 30 min. before using the spores in the respirometric experiments. Pre-activated spores were always washed free of furfural before they were added to the respirometer vessels. In all cases, the suspending medium was distilled water.

Dry weights of spore samples were determined by pipetting aliquots onto tared glass cover slips which were then dried overnight in an oven at $105^{\circ} \mathrm{C}$.

REsults.-The response of "fresh" spores to furfural treatment.-The effects of $5 \times 10^{-4} \mathrm{M}$ furfural upon the respiratory metabolism of "fresh" ascospores were first investigated. As can be seen in fig. 1, the curves for $\mathrm{CO}_{2}$ output and oxygen uptake are more or less parallel, although the amount of $\mathrm{CO}_{2}$ given off seems to be consistently higher than that for oxygen uptake. At this concentration of furfural, a 17-fold increase in oxygen uptake results. Also, a definite "lag period" ensues before the activated spores begin the rapid phase of $\mathrm{O}_{2}$ uptake. This is probably due to the delay in the penetration of furfural. Different concentrations of furfural were now used and the oxygen uptake and per cent germination determined. Fig. 2 and table I show the results of these experiments. The "lag period" is again apparent except in the case of $I X$ $10^{-5} \mathrm{M}$ where the small amount of uptake makes it difficult to observe. Although $5 \times 10^{-2} \mathrm{M}$ furfural induces a definite increase in oxygen uptake, this increase is considerably smaller than that for all concentrations except $\mathrm{I} \times 10^{-5} \mathrm{M}$. Moreover, no germination occurs at this concentration. However,

TABL: 1. The effect of different concentrations of furfural upon the $Q_{o_{2}}$ and germination of ascospores of Neurospora tetrasperma.

\begin{tabular}{|c|c|c|c|}
\hline \multirow{2}{*}{$\begin{array}{c}\text { Furfural } \\
\text { concentration }\end{array}$} & \multirow[b]{2}{*}{$\mathrm{Q}_{2}{ }^{*}$} & \multicolumn{2}{|c|}{$\begin{array}{l}\% \text { germination } \\
\text { Time after activation (min. } \\
\text { after tipping furfural) }\end{array}$} \\
\hline & & 335 & 570 \\
\hline & & \multicolumn{2}{|c|}{$\min }$. \\
\hline 0 & 0.54 & 0 & 0 \\
\hline $5 \times 10^{-2} \mathrm{M}$ & 1.3 & 0 & 0 \\
\hline $1 \times 10^{-2} \mathrm{M}$ & 7.1 & $0^{\mathrm{b}}$ & 17 \\
\hline $1 \times 10^{-3} \mathrm{M}$ & 7.8 & 28 & 37 \\
\hline $1 \times 10^{-4} \mathrm{M}$ & 3.9 & 14 & 12 \\
\hline $1 \times 10^{-5 M}$ & 1.3 & 2.8 & ---- \\
\hline
\end{tabular}

" $\mathrm{Q}_{2}$ calculated from the oxygen consumption during the time interval $290-350 \mathrm{~min}$. after activation.

${ }^{b}$ Germinal buds were extended, but the germ tubes were not yet formed. 

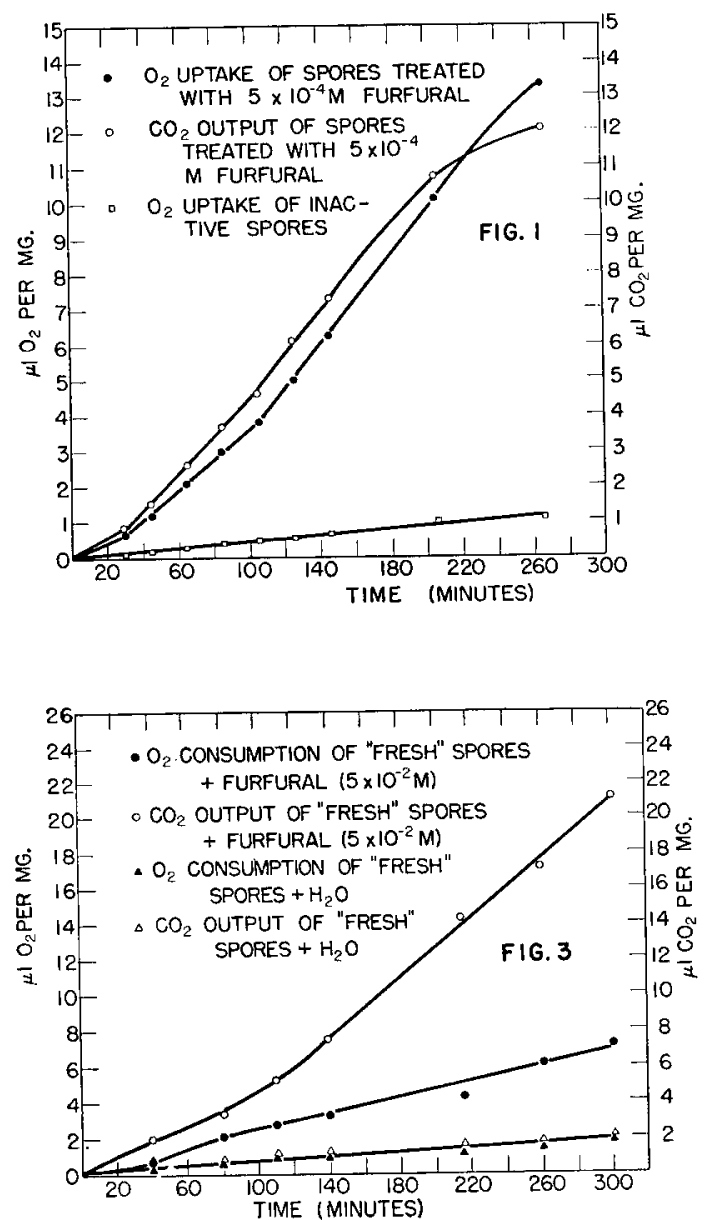
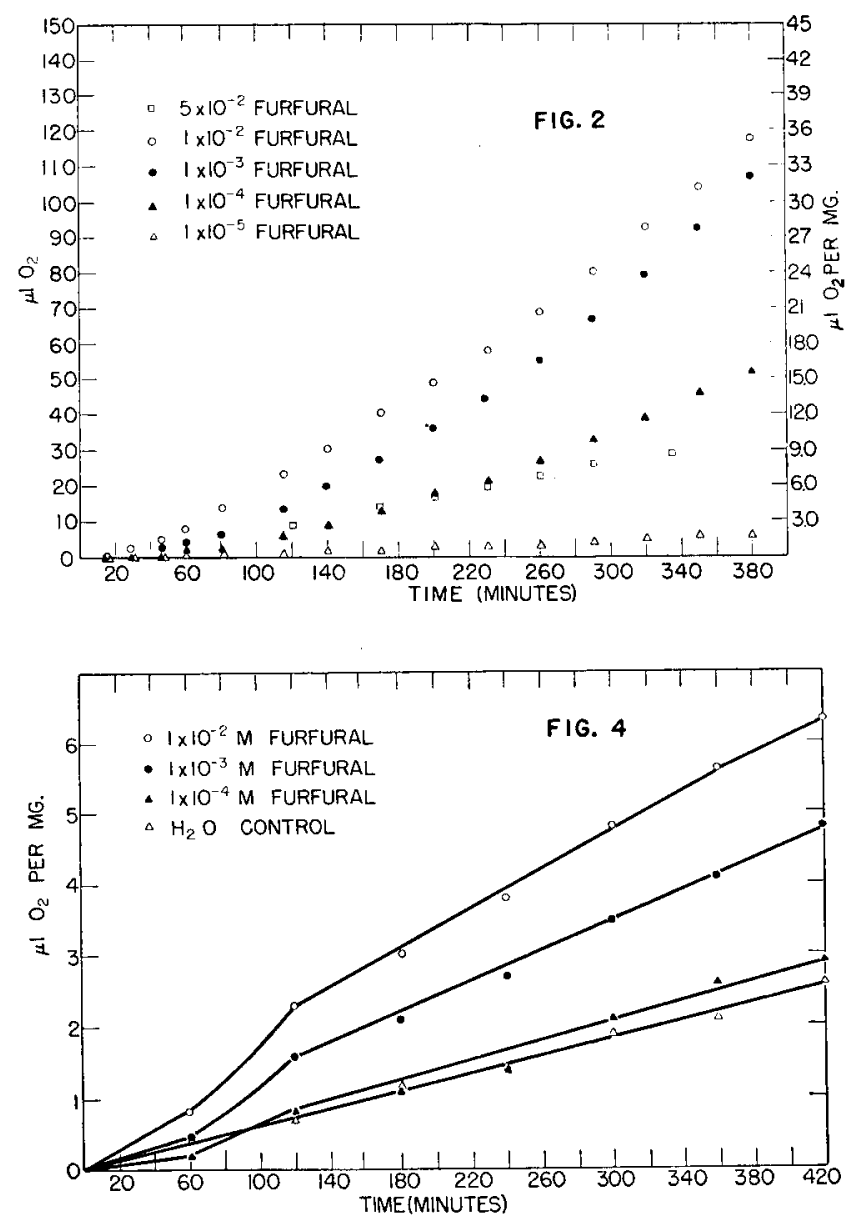

Fig. 1-4.-Fig. 1. Effect of furfural upon the respiration of "fresh" ascospores of Neurospora tetrasperma. Ascospores were used 3 days after harvesting.-Fig. 2. Effect of different concentrations of furfural upon the oxygen uptake of "fresh" ascospores of Neurospora tetrasperma. Ascospores were used 5 days after harvesting.-Fig. 3 . Effect of high concentrations of furfural $\left(5 \times 10^{-2} \mathrm{M}\right)$ upon the respiration of "fresh" ascospores of Neurospora tetrasperma. Ascospores were used 19 days after harvesting.-Fig. 4. Effect of furfural upon the oxygen uptake of "old" ascospores of Neurospora tetrasperma. Ascospores were used approximately $9 \mathrm{mos}$. after harvesting. In all cases where the $\mu 10_{2}$ are calculated per mg., the dry weights were used. Measurements were begun (zero time) from the instant of tipping of furfural.

if spores which were incubated in $5 \times 10^{-2} \mathrm{M}$ furfural for $8 \mathrm{hr}$. were washed in distilled water and reincubated in water, germination occurred. Every other concentration of furfural used induced some germination and, with concentrations from $1 \times$ $10^{-3} \mathrm{M}$ through $1 \times 10^{-5} \mathrm{M}$, the per cent germination was proportional to the logarithm of the concentration of furfural. Some delay in germination was apparent with $1 \times 10^{-2} \mathrm{M}$ despite the fact that the "lag period" of oxygen uptake was the smallest of all the concentrations that were tested.

The spores used in the above experiments were also activated by heat treatment as described previously. The average $\mathrm{Q}_{\mathrm{O}_{2}}$ of two separate experiments, as calculated from the period 150-230 min. after activation, was 8.5 with 85 per cent germination.

The toxic effect of $5 \times 10^{-2} \mathrm{M}$ furfural was fur- ther investigated by determining the $\mathrm{CO}_{2}$ output of treated spores. Fig. 3 shows that there is about 3 times more $\mathrm{CO}_{2}$ given off than oxygen taken up.

Several concentrations of furfural were now added to ascospores under anaerobic conditions, but activation was not accomplished under these conditions with any concentration used. The $\mathrm{Q}_{\mathrm{CO}_{2}}^{\mathrm{N}_{2}{ }^{2}}$ was not significantly higher than that of the controls in any case except that of $5 \times 10^{-2} \mathrm{M}$ where the $\mathrm{Q}_{\mathrm{CO}_{2}}^{\mathrm{N}_{2}}$ was equal to the $\mathrm{Q}_{\mathrm{CO}_{2}}^{\text {air }}{ }^{3}$ (3.0). Even though oxygen was reintroduced after $18 \mathrm{hr}$., no activation occurred.

When ascospores were activated in air by furfural, and immediately subjected to anaerobic con${ }^{2} \mathrm{Q}_{\mathrm{Co}_{2}}^{\mathrm{N}_{2}}$ was calculated as $\mathrm{mm} .{ }^{3} \mathrm{CO}_{2} / \mathrm{mg}$. $/ \mathrm{hr}$. in nitrogen. ${ }^{3} \mathrm{Q}_{\mathrm{CO}_{2}}^{\mathrm{alr}}$ was calculated as $\mathrm{mm} .{ }^{3} \mathrm{CO}_{2} / \mathrm{mg}$. $/ \mathrm{hr}$. in air. 
ditions by bubbling in nitrogen, the results shown in table 2 were obtained. After $60 \mathrm{~min}$., the rate of $\mathrm{CO}_{2}$ production was higher in the case of the spores incubated anaerobically as compared with those incubated aerobically. However, after 430 min., the rate of anaerobic $\mathrm{CO}_{2}$ production dropped sharply, while the aerobic $\mathrm{CO}_{2}$ production increased during this time. Germination was checked 4.85 min. after furfural was added and about 40 per cent of the spores incubated aerobically had germinated while none of those incubated anaerobically had done so.

In order to determine whether penetration could be effected anaerobically, ascospores were treated with $1 \times 10^{-3} \mathrm{M}$ furfural for $45 \mathrm{~min}$. under $\mathrm{N}_{2}$. At the end of this time, air was reintroduced and the ascospores were immediately washed free of furfural by means of four changes of distilled water. After incubation at $26^{\circ} \mathrm{C}$. for $8 \mathrm{hr}$., germination was observed to have occurred in all vessels.

TABLE 2. The respiratory gas exchange of ascospores of Neurospora tetrasperma which were activated aerobically and anaerobically in $5 \times 10^{-4} \mathrm{M}$ furfural.

\begin{tabular}{|c|c|c|c|}
\hline \multirow{2}{*}{\multicolumn{2}{|c|}{ Min. after activation }} & \multicolumn{2}{|c|}{ Spores incubated } \\
\hline & & in $\mathrm{N}_{2}$ & in air \\
\hline $\mathrm{Q}_{2}^{\mathrm{N}_{2}}:$ & $\begin{array}{l}60 \mathrm{~min} . \\
430 \mathrm{~min} .\end{array}$ & $\begin{array}{l}2.6 \\
0.17\end{array}$ & $\cdots$ \\
\hline$Q_{\mathrm{CO}_{2}}^{\mathrm{alr}}:$ & $\begin{array}{l}60 \mathrm{~min} . \\
430 \mathrm{~min} .\end{array}$ & - & $\begin{array}{l}1.3 \\
1.94\end{array}$ \\
\hline $\mathrm{Q}_{\mathrm{O}_{2}}:$ & $\begin{array}{r}60 \mathrm{~min} . \\
430 \mathrm{~min} .\end{array}$ & $\ldots$ & $\begin{array}{l}0.79 \\
4.6\end{array}$ \\
\hline
\end{tabular}

The response of "old" spores to furfural.--The response of "old" spores to furfural activation was also investigated, with the results shown in fig. 4 . As with the "fresh" spores, a "lag period" followed by a period of increased rate of oxygen uptake is demonstrated by "old" spores. However, these increased rates are not sustained, for at about 120 min. after tipping they fall to a level only slightly higher than that of dormant spores. There was no enhancement of the germination of "old" spores in the presence of furfural.

Finally, the response of "old" spores to $5 \times$ $10^{-2} \mathrm{M}$ furfural was investigated, as was done previously for "fresh" spores. As fig. 5 shows, the rate of gas exchange increases sharply during the interval from 60-90 min. after tipping, but drops off thereafter. As in the case of fresh spores, the $\mathrm{CO}_{2}$ output is greater than the oxygen uptake. Table 3 gives the comparative values for the $Q_{o_{2}}{ }^{4}$ and $\mathrm{Q}_{\mathrm{CO}_{2}}$ of "fresh" and "old" spores when treated with $5 \times 10^{-2} \mathrm{M}$ furfural.

Discussion.-Ascospores treated with furfural

${ }^{4} \mathrm{Q}_{2}$ was calculated as $\mathrm{mm} .{ }^{3} \mathrm{O}_{2} / \mathrm{mg} . / \mathrm{hr}$.

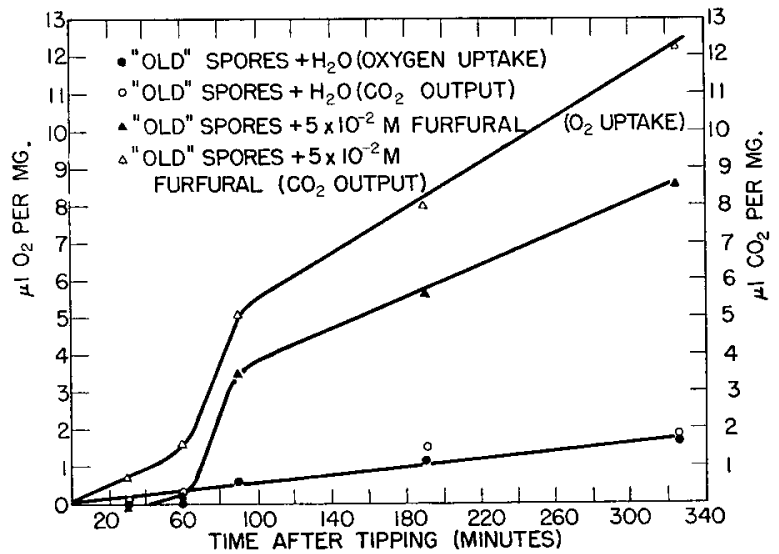

Fig. 5. Effect of high concentrations of furfural $(5 \times$ 10-2 M) upon the respiration of "old" ascospores of Neurospora tetrasperma. Ascospores were used approximately 9 mo. after harvesting. Other details as in previous figures.

show a marked rise in respiratory rate as a result of activation. This rise is comparable to that of heat-activated ascospores in the experiments of Goddard $(1935,1939)$. The magnitude of this increase is approximately the same since Goddard reported 10-40-fold more oxygen uptake in activated spores as compared with the 15-20-fold increase found in these experiments. The evidence for a second increase in respiratory rate, as reported by Goddard (1935), is not as clear cut. This may be explained in part by the shape of the curves drawn by Goddard, who drew straight lines joining the points of his activation curves, and by the differences in the means of activation. As a result of the present ex. periments, it was felt that an exponential curve most nearly fit the data and under these conditions, the secondary rise noted by Goddard is either ab. sent or comes in at a much later time than he reported. It is suggestive, perhaps, that the shape of the activation curves resembles that obtained for adaptive enzymes, although this offers no explanation of the mechanism by which activation occurs (cf. Spiegelman, p. 276, 1950). Further work is now in progress in this laboratory to investigate the possibility that the formation of an adaptive enzyme or enzymes can be related to the activation process.

TABle 3. A comparison of the effects of $5 \times 10^{-2} M$ fur. fural upon the $\mathrm{QO}_{2}$ " and $\mathrm{QCo}_{2}$ " of "fresh" and "old" ascospores of Neurospora tetrasperma.

\begin{tabular}{ccccc}
\hline \hline \multicolumn{2}{c}{ "Old" spores } & & \multicolumn{2}{c}{ "Fresh" spores } \\
\cline { 5 - 6 } $\mathrm{Q}_{\mathrm{O}_{2}}$ & $\mathrm{Q}_{\mathrm{co}}$ & & $\mathrm{Q}_{2}$ & $\mathrm{Q}_{\mathrm{Co}_{2}}$ \\
1.2 & 1.8 & & 1.3 & 5.5
\end{tabular}

${ }^{a}$ The $\mathrm{Qo}_{2}$ and $\mathrm{QCO}_{2}$ were calculated from the gas exchange during the time interval $180-300 \mathrm{~min}$. after furfural was tipped. 
In these experiments, the $\mathrm{Q}_{\mathrm{O}_{2}}$ and the per cent germination of furfural-activated ascospores were always smaller than the figures obtained with heatactivated ascospores. It is possible that the optimal concentration of furfural is an intermediate one not used in these experiments, or that the spore lots used had lost some sensitivity to the chemical activator. That both possibilities may exist is suggested by subsequent unpublished experiments of this author wherein different spore lots and intermediate concentrations were used. In these experiments, the results approximated those obtained by heat activation.

The per cent germination and the $\mathrm{Q}_{\mathrm{O}_{2}}$ are approximately proportional to the logarithm of the concentration of furfural only below $1 \times 10^{-3} \mathrm{M}$. Although $1 \times 10^{-2} \mathrm{M}$ induces a 15 -fold increase in respiratory activity, germination is delayed. The highest concentration used, $5 \times 10^{-2} \mathrm{M}$, did not permit germination unless the spores were washed free of the chemical and also induced a striking increase in $\mathrm{CO}_{2}$ output which was more than 4 times that shown by the oxygen uptake. This effect has not yet been investigated further, but might suggest the ability of the cell to metabolize furfural with the release of $\mathrm{CO}_{2}$ under these conditions.

As in the case of heat-activated spores, furfuraltreated ones do not germinate unless incubated aerobically after exposure to this chemical. Permeability alone cannot be responsible for this because these experiments have shown that furfural penetrates the spores under anaerobic as well as aerobic conditions. That toxic products may be produced during anaerobic incubation in furfural is suggested by the failure of spores treated in this way to germinate even after air is reintroduced.

The response of "old" spores to furfural is quite different from that shown by "fresh" spores. In contrast to the latter, "old" spores do not germinate upon furfural treatment. Some insight into the reasons for this may be gained by consulting fig. 4, which shows that after a preliminary increase, the rate of gas exchange falls to a level about twice that of the control. Since there is this marked initial stimulation, it is apparent that penetration is not a factor in the effect of furfural upon "old" spores. In fact, the slopes of the steepest portions of the curves are not very greatly different from the corresponding curves for "fresh" spores. The greatest difference between the behavior of these spores of different age lies in the fact that the rate of gas exchange of the "old" spores falls markedly after 90 min., and finally is maintained at a level about twice that of its dormant rate. What is suggested is that the initial step or steps in the activation proc. ess, as expressed by the steep increase in gas exchange during the period from $60-90 \mathrm{~min}$., can be performed by "old" spores, but that the maintenance of this rate is dependent upon another reaction or reactions which cannot be undertaken by these spores.

That penetration of furfural is probably not responsible for the difference between "fresh" and "old" spores is suggested by the response of "old" spores to $5 \times 10^{-2} \mathrm{M}$ furfural. In this case, there is also a pronounced increase in the rate of gas exchange followed by the decrease to a slower rate, so that the chemical is almost certainly entering the cell. What is also of interest are the data in table 2 which show that there is no significant difference in the $\mathrm{Q}_{\mathrm{O}_{2}}$ of "fresh" and "old" spores treated with $5 \times 10^{-2} \mathrm{M}$ furfural. This suggests that the reason for the loss in sensitivity of "old" spores to furfural activation might be sought in the $\mathrm{CO}_{2}$-producing mechanisms of the cell.

\section{SUMMARY}

As a result of activation by furfural, dormant freshly harvested ascospores of Neurospora tetrasperma show a 15-20-fold increase in oxygen uptake and carbon dioxide evolution. The per cent germination and the $Q_{O_{2}}$ are approximately proportional to the logarithm of the concentration of furfural, below $1 \times 10^{-3} \mathrm{M}$. Higher concentrations delay or inhibit germination although this effect is reversible. Spores which have lost their sensitivity to furfural ("old" spores) show only a transitory increase in respiratory rate with little increased germination. Activation of "fresh" ascospores does not occur anaerobically although furfural can penetrate under these conditions.

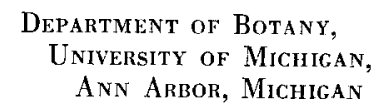

\section{LITERATURE CITED}

Emerson, Mary R. 1948. Chemical activation of ascospore germination in Neurospora crassa. Jour. Bact. 55: $327-330$.

GoDDARD, D. R. 1935. The reversible heat activation inducing germination and increased respiration in the ascospores of Neurospora tetrasperma. Jour. Gen. Physiol. 19: 45-60.

- 1939. The reversible heat activation of respiration in Neurospora. Cold Spring Harbor Symp. Quant.
Biol. 7 : 362-376.

Spiecklman, S. 1950. Modern aspects of enzymatic adaptation. In The enzymes. J. R. Sumner and K. Myrback, Ed. Vol. 1, p. 267-306. Academic Press. New York.

Sussman, A. S. 1953. The effect of heterocyclics and other compounds upon the germination of ascospores of Neurospora tetrasperma. Jour. Gen. Microbiol. 8: 211216. 